\title{
Identification of Surrogate Biomarkers for the Prediction of Patients at Risk of Low Macular Pigment in Type 2 Diabetes
}

\author{
Grainne Scanlon \\ Technological University Dublin, grainne.scanlon@tudublin.ie \\ Daniel McCartney \\ Technological University Dublin, daniel.mccartney@tudublin.ie \\ John Butler \\ TU Dublin, john.s.butler@tudublin.ie
}

See next page for additional authors

Follow this and additional works at: https://arrow.tudublin.ie/otpomart

Part of the Optometry Commons

\section{Recommended Citation}

Scanlon, G. et al. (2019): Identification of Surrogate Biomarkers for the Prediction of Patients at Risk of Low Macular Pigment in Type 2 Diabetes, Current Eye Research, DOI: 10.1080/02713683.2019.1635166

This Article is brought to you for free and open access by ARROW@TU Dublin. It has been accepted for inclusion in Articles by an authorized administrator of ARROW@TU

Dublin. For more information, please contact arrow.admin@tudublin.ie, aisling.coyne@tudublin.ie, gerard.connolly@tudublin.ie.

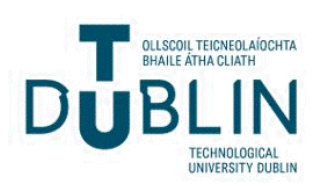




\section{Authors}

Grainne Scanlon, Daniel McCartney, John Butler, Ekaterina Loskutova, and James Loughman

This article is available at ARROW@TU Dublin: https://arrow.tudublin.ie/otpomart/78 
Current Eye Research

\title{
Identification of Surrogate Biomarkers for the Prediction of Patients at Risk of Low Macular Pigment in Type 2 Diabetes
}

\author{
Grainne Scanlon, Daniel McCartney, John S Butler, Ekaterina Loskutova \& \\ James Loughman
}

To cite this article: Grainne Scanlon, Daniel McCartney, John S Butler, Ekaterina Loskutova \& James Loughman (2019): Identification of Surrogate Biomarkers for the Prediction of Patients at Risk of Low Macular Pigment in Type 2 Diabetes, Current Eye Research, DOI: 10.1080/02713683.2019.1635166

To link to this article: https://doi.org/10.1080/02713683.2019.1635166

Accepted author version posted online: 21

Jun 2019.

Published online: 02 Jul 2019.

Submit your article to this journal $\pi$

山 Article views: 28

View Crossmark data $₫$ 


\title{
Identification of Surrogate Biomarkers for the Prediction of Patients at Risk of Low Macular Pigment in Type 2 Diabetes
}

\author{
Grainne Scanlon ${ }^{\mathrm{a}}$, Daniel McCartney ${ }^{\mathrm{b}}$, John S Butler ${ }^{\mathrm{a}, \mathrm{c}}$, Ekaterina Loskutova ${ }^{\mathrm{a}}$, and James Loughman ${ }^{\mathrm{a}}$
}

aCentre for Eye Research Ireland, School of Physics, Clinical \& Optometric Sciences, Environmental Sustainability and Health Institute, Technological University Dublin, Dublin, Ireland; 'bchool of Biological and Health Sciences, Technological University Dublin, City Campus, Dublin, Ireland; ' $S c h o o l$ of Mathematical Sciences, Technological University Dublin, City Campus, Dublin, Ireland

\begin{abstract}
Purpose: This cross-sectional study compared macular pigment (MP) levels among persons with Type 2 diabetes relative to healthy controls. Additionally, a range of behavioral, anthropometric, clinical and serum measures were explored as possible predictors of low MP optical density (MPOD) in diabetes.

Methods: Two health status groups; Group 1: Type 2 diabetes $(n=188)$, and Group 2: Healthy controls ( $n=2,594)$ completed a full MP assessment using customized heterochromatic flicker photometry, as part of The Irish Longitudinal Study on Aging (TILDA). Clinical [blood pressure; cataract status; MPOD] and anthropometric [waist $(\mathrm{cm})$; weight $(\mathrm{kg})$; hip $(\mathrm{cm})$ ] measurements were taken, and a blood sample drawn for analysis of serum biomarkers [lipoproteins; inflammatory markers (C reactive protein and vitamin-D)].

Results: One-way ANOVA revealed lower MPOD in subjects with Type 2 diabetes relative to controls $(p=.047)$. Amongst participants with diabetes, those with low serum vitamin $D(\leq 50 \mathrm{nmol} / \mathrm{L})$ had significantly lower mean MPOD compared to those with sufficient serum vitamin $D$ levels $>50 \mathrm{nmol} / \mathrm{L}$ $(0.173(0.148)$ vs. $0.226(0.145) ; p=.006)$. Concomitantly, MP was significantly lower in diabetes participants with raised serum triglyceride (TG) to high density lipoprotein (HDL) ratio (TG/HDL); values $>1.74 \mathrm{mmol} / \mathrm{L}(0.172(0.140)$ vs $0.215(0.152) ; p=.039)$. Body mass index, waist-to-height ratio and waist circumference, were all significantly negatively correlated with MPOD (Pearson's correlation, $p<.05$ for all). Significant correlates of MPOD in the multivariate regression model included smoking, cataract, and vitamin D, which collectively contributed $18.5 \%$ of the overall variability in MPOD status amongst participants with Type 2 diabetes.

Conclusions: This study provides additional evidence that low MP may indeed be a feature of Type 2 diabetes, and further identifies smoking, cataract and vitamin D status as plausible predictors of low MPOD amongst persons with Type 2 diabetes.
\end{abstract}

ARTICLE HISTORY

Received 23 April 2019

Revised 18 June 2019

Accepted 18 June 2019

\section{KEYWORDS}

Macular pigment; high density lipoprotein; triglycerides; vitamin D; oxidative stress

\section{Introduction}

The prevalence of diabetes has been increasing steadily over recent decades and is now reaching epidemic proportions. ${ }^{1}$ Type 1 and Type 2 diabetes are the two main forms of diabetes, however, Type 2 diabetes is much more common and is estimated to affect more than 500 million people worldwide. ${ }^{2}$ Diabetic retinopathy (DR), a debilitating microvascular complication of diabetes, is the most common cause of vision loss in people with diabetes and is a leading global cause of vision impairment and blindness among working-age adults. ${ }^{3}$

The pathogenesis of DR is multifactorial and remains poorly understood. Chronic hyperglycemia induces oxidative stress in the retina ${ }^{4}$, and it is thought that hyperglycaemia causes tissue damage through a number of major pathways, including the polyol pathway, activation of protein kinase $\mathrm{C}$ (PKC), upregulation of advanced glycation end product formation and activity of the hexosamine pathway. ${ }^{5}$ Interaction of these biochemical pathways may cause a cascade of events, such as apoptosis, oxidative stress, inflammation and angiogenesis, which can lead to damage of the diabetic retina, as reviewed by Al-Kharashi. ${ }^{6}$ It is thought that hyperglycemia leads to a dysregulation of inflammation, which in turn leads to an increase in the level of proinflammatory proteins. ${ }^{7}$ Inflammatory processes underlie many of the functional retinal vasculature alterations observed histologically in early DR. ${ }^{8}$ Animal and human studies have confirmed that all retinal cell types, including inner retinal neurons, Muller cells and astrocytes, are damaged by diabetes. ${ }^{9}$ Recognizing both the clinical and histological aspects of retinal change in diabetic macular edema and DR is essential to understanding the mechanisms of vision loss in diabetes, and in developing early-stage clinical interventions that effectively target the specific etiologies and underlying pathological mechanisms of the condition. In fact, insulin resistance, impaired glucose tolerance and Type 2 diabetes may exist for many years before clinical retinal signs become evident. $^{10}$

CONTACT Grainne Scanlon grainne.scanlon@dit.ie School of Physics, Clinical \& Optometric Sciences, The National Optometry Centre, Kevin Street, Dublin 8, Ireland

Color versions of one or more of the figures in the article can be found online at www.tandfonline.com/icey.

(c) 2019 Taylor \& Francis Group, LLC 
The body's natural defence against oxidative damage and inflammation is the neutralization of reactive oxygen species (ROS) with endogenous antioxidants, both enzymatic and nonenzymatic. ${ }^{11}$ These endogenous antioxidants work with exogenous antioxidants (vitamin $\mathrm{C}$, vitamin $\mathrm{E}$ and carotenoids such as beta carotene, lutein, zeaxanthin and meso-zeaxanthin), ${ }^{12}$ together balancing redox status. The carotenoids, lutein, zeaxanthin and meso-zeaxanthin, collectively known in the eye as macular pigment (MP); confer potent anti-oxidant and anti-inflammatory effects at the macula. ${ }^{13,14}$ These carotenoids are uniquely concentrated in the inner and central layers of the primate macula, and while there have been numerous studies looking at the role of carotenoids and other nutrients in the prevention of AMD, reviewed elsewhere, ${ }^{15}$ the association between diabetes and MPOD levels, however, has received somewhat less attention.

The evidence that does exist, however, suggests that the relationship is worth exploring in more detail. Serum concentrations of lutein and zeaxanthin have been observed to be significantly lower in patients with DR. ${ }^{16}$ Furthermore, MP has been found to be significantly lower in patients with diabetes, ${ }^{17}$ with one study reporting lower levels of MP in Type 2 versus Type 1 patients. ${ }^{18}$ It is also possible that MP may confer therapeutic benefits in diabetic eye disease. A number of studies have explored the effect of MP supplementation in diabetes. Although the evidence is far from definitive, improvements in structural and functional measures of ocular health in response to macular carotenoid supplementation have been found. The earliest of these studies reported improvements in vision and macular edema following supplementation. ${ }^{16}$ The diabetes visual function supplement study (DiVFuSS) suggested that a nutritional supplement containing lutein and zeaxanthin mitigated the damaging effects of systemic inflammation on ocular function, and that these beneficial effects may have been mediated by enhancements in MPOD. ${ }^{19}$ Improvements in visual function have also been observed in patients with diabetes following supplementation, including in contrast sensitivity ${ }^{20}$ and in electrophysiological indices of retinal function. ${ }^{21}$

The reasons why MPOD levels might be adversely affected in diabetes are yet to be elucidated, but a number of factors might be important. At presentation, Type 2 diabetes is most often accompanied by other co-morbidities including overweight/obesity, insulin resistance, hypertension and dyslipidemia, ${ }^{22}$ which may adversely affect MP by compromising the availability, ${ }^{23}$ transport, ${ }^{24}$ assimilation ${ }^{24}$ and maintenance/retention of dietary carotenoids in the retina. De novo synthesis of carotenoids is not possible in humans, therefore, the chronic low-grade inflammation ${ }^{7}$ and pro-oxidative environment ${ }^{4}$ associated with Type 2 diabetes may negatively impact MPOD levels in the eye.

Macular pigment levels can be measured in vivo, but are not routinely measured in clinical practice. Given the possibility that higher levels of MP may be beneficial for vision and ocular health in diabetes, the investigation of surrogate indicators of MP status that are more readily and routinely measured is merited. The capacity of such an alternate biomarker to expedite the identification and treatment of patients at risk of low MP could be particularly important given that retinal damage can occur long before visual signs of DR are evident. This study was designed, therefore, to compare MPOD in participants with and without Type 2 diabetes and, more importantly, to explore a range of behavioral, anthropometric, clinical and serum biomarkers as possible predictors of risk for low MPOD among individuals with Type 2 diabetes.

\section{Methods}

\section{Study population}

The Irish Longitudinal Study on Ageing (TILDA) is a large prospective cohort study examining the social, economic and health factors which influence healthy ageing in older adults resident in Ireland. ${ }^{25}$ Cross-sectional data from TILDA was analyzed in this study. A stratified clustered sample of 8,175 individuals, representative of the population of Ireland, aged 50 years and over, participated in Wave 1 of this study, which took place between October 2009 and July 2011. The study design of TILDA has been described in detail elsewhere. ${ }^{25}$ Health and lifestyle data were captured in participants' own homes using computerized aided personal interview (CAPI) ${ }^{26}$ The presence or absence of eye pathology was determined using the CAPI with the question "has a doctor ever told you if you had any of the following conditions: diabetes, AMD, cataracts or glaucoma". Participants were also asked whether they had ever been told by a doctor if they had high cholesterol or high blood pressure. Participants were asked to record all medications that they took on a regular basis, including those related to diabetes, such as oral hypoglycaemic agents (OHAs) and/or insulin, which were coded using the Anatomic Therapeutic Classification (ATC) system. Participants were asked if they currently smoked or had ever smoked cigarettes regularly (daily for at least a year), and were categorized as never smoked, past smokers or current smokers. The International Physical Activity Questionnaire (IPAQ) was used to classify participants' level of physical activity into low, moderate or high levels. All participants were invited to attend a health assessment in one of two locations, Dublin or Cork. Macular pigment measurement was only conducted on participants who attended a health center, therefore, a number of participants were automatically excluded from the current analysis: i.e. if they were unable to travel to a health center or opted for a home assessment instead $(\mathrm{n}=881)$ and/or refrained from having either a home or health assessment $(n=2,267)$. A total of 5027 individuals participated in a health assessment, carried out by trained research nurses (Figure 1). This research adhered to the tenets of the Declaration of Helsinki and was approved by the Technological University Dublin Research Ethics Committee. All participants provided written informed consent prior to participation in the study.

\section{Diabetes classification}

Diabetes type was classified into 'no diabetes', 'prediabetes', 'diagnosed diabetes' and 'undiagnosed diabetes'. Diagnosed diabetes was identified from the CAPI with the 


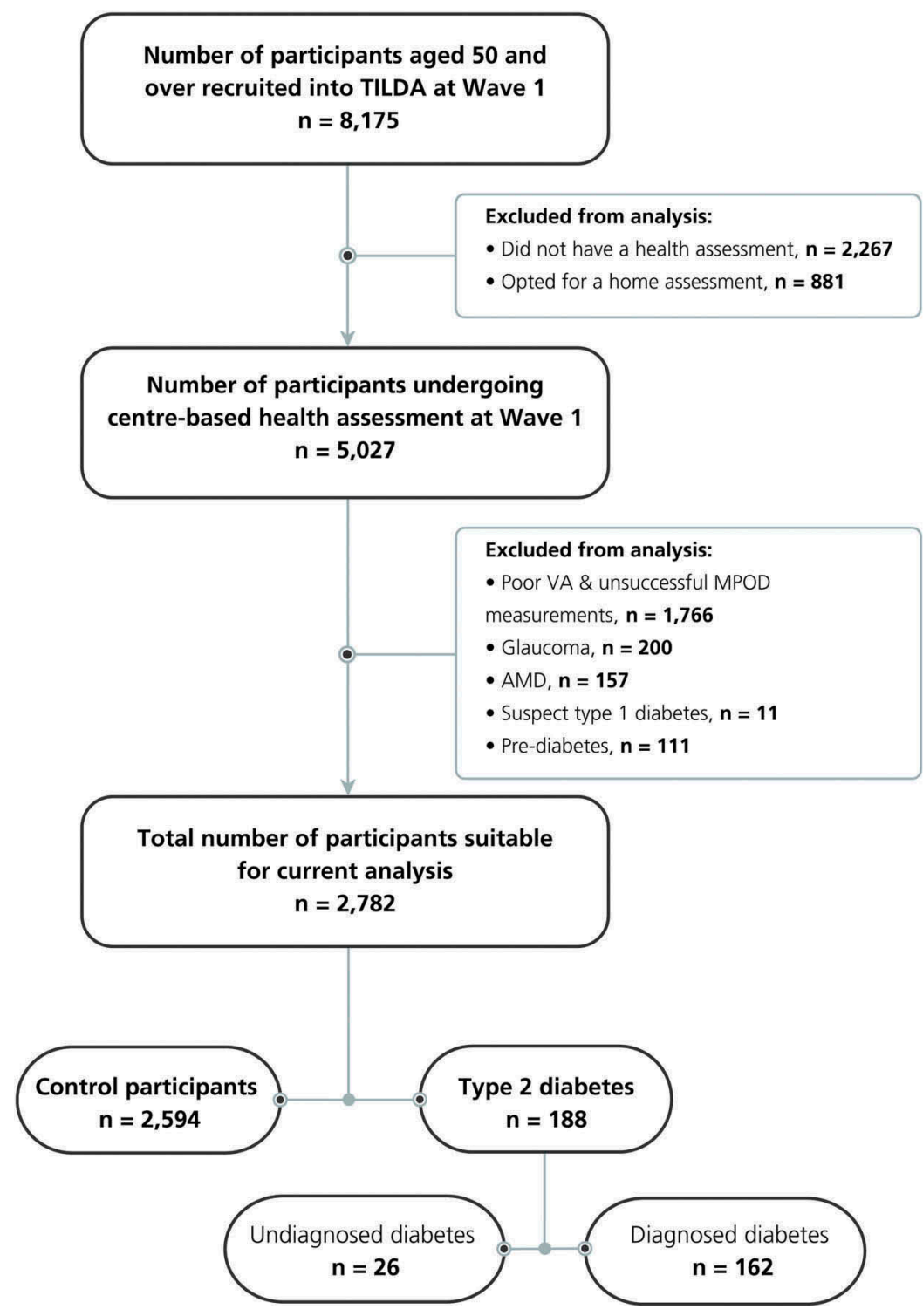

Figure 1. Population included in analysis.

Abbreviations: AMD, age-related macular degeneration; MPOD, macular pigment optical density, n, number of participants; TILDA, The Irish Longitudinal Study on Ageing; VA, Visual Acuity.

question 'has a doctor ever told you that you have diabetes or high blood sugar?' and also from prescribed diabetes medications at the time of the interview, identified using the ATC codes 'A10A' for insulin and 'A10B' for oral hypoglycemic medications. A blood sample was provided for serum analysis. Glycated haemoglobin (HbAlc), a long-term indicator of glycaemic control, was measured and participants were further classified as having 'pre-diabetes,' and 'undiagnosed diabetes' against American Diabetes Association cut-off values. ${ }^{27}$ The TILDA protocol for blood sample collection, processing and storage has been described previously. ${ }^{26}$ Eleven respondents who reported a doctors diagnosis of diabetes before the age of 40 and who were on insulin therapy at the time of interview were excluded from analysis due to the suspicion that they might have Type 1 diabetes, in line with previously published data, ${ }^{28}$ (Figure 1). Duration of disease was quantified by asking those with a previous diagnosis 'how old they were when first diagnosed?'

\section{Macular pigment optical density assessment}

Corrected visual acuity was measured in both eyes using the Early Treatment Diabetic Retinopathy Study (ETDRS) LogMAR chart at a distance of 4 metres, using the participants existing prescription where necessary. The eye with the best visual acuity was chosen for the MP assessment or if there was equal vision in both eyes, the right eye was chosen. MPOD was measured by customized heterochromatic flicker photometry (c-HFP) centrally at $0.5^{\circ}$ of retinal eccentricity using the Macular Metrics Densitometer (Macular Metrics, Rehoboth, MA). The established method employed for measuring MP has been described in detail previously. ${ }^{29}$ Of the 5,027 participants who attended a health assessment, 2,904 
were able to successfully complete MPOD assessment (participants with diabetes, $\mathrm{n}=310$; non-diabetic controls, $\mathrm{n}=2,594)$. A number of subjects were excluded from the overall MPOD analysis $(n=2,123)$ and possible reasons for this included: poor fixation, technical issues, poor visual acuity (visual acuity $6 / 18$ Snellen $(\leq 0.5$ LogMAR)) and retinal pathology (AMD, glaucoma). Because Type 1 and 2 diabetes are considered different clinical conditions, the presenting features of the condition (adiposity, dyslipidaemia, oxidative stress and inflammation) may not be uniform across both and may have different relationships with MPOD, therefore, a number of participants with suspect Type 1 diabetes $(\mathrm{n}=11)$, were excluded from the current study. Participants with pre-diabetes (HbAlc: 5.7-6.4\%) were also excluded from the current analysis $(n=122)$. Of the 8,500 participants that took part in Wave 1 of TILDA, 188 Type 2 diabetes participants and 2,594 controls were deemed suitable for the study (Figure 1).

\section{Anthropometric assessment}

Height $(\mathrm{cm})$ and weight $(\mathrm{kg})$ were measured to one decimal place as described in detail elsewhere. ${ }^{26}$ Body mass index (BMI) was calculated from measured height and weight as: weight $(\mathrm{kg}) /$ height $\left(\mathrm{m}^{2}\right)$. Waist circumference (WC) and hip were measured to the nearest $\mathrm{cm}$. Waist-to-height ratio (WHtR) and waist-to-hip ratio (WHpR) were calculated based on these measured data. Cut-offs were applied to classify participants as obese or non-obese for the following variables (BMI; WC; WHtR and WHpR). ${ }^{30}$

\section{Blood pressure}

Two blood pressure (BP) measurements were taken using the $\mathrm{OMRON}^{\mathrm{TM}}$ digital automatic blood pressure monitor (Model M10-IT) with arm cuff. ${ }^{26}$ Seated mean systolic $(\mathrm{mmHg})$ and mean diastolic (mmHg) BP were used for analysis. The participant was defined as hypertensive if mean seated systolic BP exceeded $140 \mathrm{mmHg}$ or mean seated diastolic BP exceeded $90 \mathrm{mmHg}$.

\section{Serum analysis}

Respondents were not asked to fast before the health assessment. Blood was extracted using defined phlebotomy protocols, ${ }^{26}$ and analyzed for a complete lipid profile, which included total cholesterol (TC), high density lipoprotein (HDL), low density lipoprotein (LDL) and triglycerides (TG), measured in millimoles per litre (mmol/L). TG to HDL ratio, TC to HDL ratio and non-HDL cholesterol (TC minus HDL) were calculated for subsequent analyses. Cut-offs were applied to indicate high or ideal serum lipid levels as per 2016 European Society of Cardiology (ESC)/ European Atherosclerosis Society (EAS) guidelines. ${ }^{31}$ Research suggests that inflammation plays a role in the development of Type 2 diabetes, ${ }^{32,33}$ therefore, anti-inflammatory marker serum vitamin D [(25(OH)D); nanomoles per litre $(\mathrm{nmol} / \mathrm{L})]$ and inflammatory marker $\mathrm{C}$ reactive protein (CRP), [micrograms per litre $(\mathrm{mg} / \mathrm{L})$ ] were also measured. Respondents were considered vitamin $\mathrm{D}$ deficient if serum levels were $\leq 50 \mathrm{nmol} / \mathrm{L}$, and sufficient if serum levels were $>50 \mathrm{nmol} / \mathrm{L}$ as per the Institute of
Medicine (IOM) vitamin D guidelines. ${ }^{34} \mathrm{~A}$ threshold of $>3.00 \mathrm{mg} /$ $\mathrm{L}$ for high and $\leq 3.00 \mathrm{mg} / \mathrm{L}$ as ideal was used for serum CRP. ${ }^{35}$

\section{Statistical analysis}

The statistical software package SPSS for Microsoft Windows (version 23.0; IBM Corp., Armonk, NY) was used for all analyses. To account for the fact that the study response rate varied among different subgroups of the population, inverse probability weights were calculated for the main sample using the Quarterly National Household Survey (2010). ${ }^{36}$ Participation rates for the health centre assessment also varied according to geographic location, health, education, age and smoking, therefore a specific "health centre weighting" was applied. A more detailed description of the weighting procedure used in TILDA is described by Barrett et al. ${ }^{36}$

Our data are presented as mean \pm standard deviation throughout. These data were tested for normality using the Kolmogorov-Smirnov test. For group comparison between participants with diabetes and non-diabetic controls, one-way analysis of variance (ANOVA) was used to test for differences in means for normally distributed parameters, while the Kruskal-Wallis test was used to test differences between group medians for non-normally distributed parameters. For categorical data, cross-tabulation with Chi-square analysis was used. The distribution of MPOD was skewed, therefore, a square root transformation of the MPOD data was performed. The derived data were normally distributed and used as the dependent variable for subsequent statistical analyses of MPOD on the diabetes group. For ease of interpretation, mean and SD of MPOD data is presented as the non-transformed original measure for Type 2 diabetes participants. Pearson's product-moment correlation tests were performed to assess the relationship between normalized MPOD and other study variables where appropriate. Boxplots and scatterplots were used to graphically highlight statistical findings. Multiple linear regression was used to investigate the un-confounded associations between behavioral, anthropometric, clinical and serum biomarker indicators and normalized MPOD. The level of statistical significance was set at $p<.05$ for all analyses.

\section{Results}

Two thousand seven hundred and eighty two subjects, analyzed as part of Wave 1 of TILDA, were divided into two study groups: Group 1: Normal controls $(\mathrm{n}=2,594)$ and Group 2: Type 2 diabetes $(\mathrm{n}=188)$. Respondents 'diagnosed with diabetes' and those with 'undiagnosed diabetes' were grouped together and classified as having Type 2 diabetes for subsequent analyses. Characteristics of the study population according to their diabetes status are presented in Table 1. Group average MPOD was $10.3 \%$ lower in participants with Type 2 diabetes $[$ mean MPOD $=0.20(0.148)]$ compared with non-diabetic controls [mean MPOD $=0.223(0.161)$ ], and this difference was statistically significant $[\mathrm{t}(2780)=-1.989$, $p=.047)$ ]. Participants with Type 2 diabetes also differed from the control group across all other demographic, behavioral, anthropometric, clinical and serum parameters examined $(p<.0001$ for all), with the exception of education 
Table 1. Characteristics of the Study Population according to Diabetic Status.

\begin{tabular}{|c|c|c|c|}
\hline & $\begin{array}{l}\text { Normal Controls } \\
(\mathrm{n}=2594)\end{array}$ & $\begin{array}{l}\text { Type } 2 \text { Diabetics } \\
(\mathrm{n}=188)\end{array}$ & $p$ \\
\hline \multicolumn{4}{|l|}{ Demographic Factors } \\
\hline Age years (Mean (SD)) & $61.40(7.62)$ & $64.73(8.32)$ & $0.0001^{*}$ \\
\hline \multicolumn{4}{|l|}{ Age category years $+(\%)$} \\
\hline $50-64$ & $68.12 \%$ & $51.06 \%$ & \multirow[t]{3}{*}{$0.0001 \neq$} \\
\hline $65-74$ & $24.94 \%$ & $35.64 \%$ & \\
\hline$>75$ & $6.94 \%$ & $13.30 \%$ & \\
\hline \multicolumn{4}{|l|}{ Sex $(\%)$} \\
\hline Male & $43.79 \%$ & $64.89 \%$ & \multirow[t]{2}{*}{$0.0001 \neq$} \\
\hline Female & $56.21 \%$ & $35.11 \%$ & \\
\hline \multicolumn{4}{|l|}{ Education (\%) } \\
\hline Primary & $18.81 \%$ & $22.34 \%$ & \multirow[t]{3}{*}{$0.174 \neq$} \\
\hline Secondary & $41.60 \%$ & $44.68 \%$ & \\
\hline Third level & $39.59 \%$ & $32.98 \%$ & \\
\hline \multicolumn{4}{|l|}{ Behavioral Factors } \\
\hline \multicolumn{4}{|l|}{ Smoking (\%) } \\
\hline Current & $13.42 \%$ & $14.89 \%$ & \multirow[t]{3}{*}{$0.027 \neq$} \\
\hline Past & $39.36 \%$ & $47.87 \%$ & \\
\hline Never & $47.22 \%$ & $37.23 \%$ & \\
\hline \multicolumn{4}{|l|}{ Alcohol (\%) } \\
\hline Yes & $78.83 \%$ & $72.87 \%$ & \multirow[t]{3}{*}{$0.130 \neq$} \\
\hline No & $18.47 \%$ & $22.87 \%$ & \\
\hline NA & $6.51 \%$ & $3.72 \%$ & \\
\hline \multicolumn{4}{|l|}{ Exercise (\%) } \\
\hline Low & $37.90 \%$ & $54.25 \%$ & \multirow[t]{3}{*}{$0.0001 \neq$} \\
\hline Moderate & $30.07 \%$ & $28.19 \%$ & \\
\hline High & $32.03 \%$ & $17.55 \%$ & \\
\hline \multicolumn{4}{|c|}{ Anthropometric \& Clinical Biomarkers (Mean (SD)) } \\
\hline $\mathrm{BMI}, \mathrm{kg} / \mathrm{m}^{2}$ & $27.98(4.42)$ & $32.32(6.25)$ & $0.0001^{*}$ \\
\hline$W C, \mathrm{~cm}$ & $93.19(12.83)$ & $105.47(13.74)$ & $0.0001^{*}$ \\
\hline WHtR & $0.56(0.070)$ & $0.63(0.08)$ & $0.0001^{*}$ \\
\hline WHpR & $0.894(0.083)$ & $0.96(0.08)$ & $0.0001^{*}$ \\
\hline Hypertensive (untreated) & $5.82 \%$ & $2.66 \%$ & $0.0001 \neq$ \\
\hline Hypertensive (treated) & $24.79 \%$ & $52.19 \%$ & \\
\hline Normotensive & $69.39 \%$ & $44.15 \%$ & \\
\hline MPOD** (Mean (SD)) & $0.223(0.161)$ & $0.20(0.148)$ & $0.047 \dagger \dagger$ \\
\hline Cataracts $(\%)$ & $6.51 \%$ & $13.83 \%$ & $0.0001 \neq$ \\
\hline \multicolumn{4}{|c|}{ Serum Biomarkers (Mean (SD)) } \\
\hline $\mathrm{TC} \mathrm{mmol} / \mathrm{L}$ & $5.24(1.04)$ & $4.27(106)$ & $0.0001^{*}$ \\
\hline $\mathrm{HDL} \mathrm{mmol} / \mathrm{L}$ & $1.59(0.44)$ & $1.27(0.33)$ & $0.0001^{*}$ \\
\hline LDL mmol/L & $3.01(0.92)$ & $2.24(0.89)$ & $0.0001^{*}$ \\
\hline $\mathrm{TG} \mathrm{mmol} / \mathrm{L}$ & $1.66(1.03)$ & $1.94(1.11)$ & $0.0001^{*}$ \\
\hline TC/HDL Ratio & $3.46(0.91)$ & $3.473(0.92)$ & $0.676^{*}$ \\
\hline TG/HDL Ratio & $1.19(0.961)$ & $1.68(1.12)$ & $0.0001^{*}$ \\
\hline Non-HDL (TC-HDL) Ratio & $3.65(0.946)$ & $2.99(0.950$ & $0.0001^{*}$ \\
\hline Vitamin $\mathrm{D} \mathrm{nmol} / \mathrm{L}$ & $59.91(25.86)$ & $51.90(22.72)$ & $0.0001^{*}$ \\
\hline CRP $\mathrm{mg} / \mathrm{L}$ & $2.83(6.95)$ & $5.23(11.94)$ & $0.0001^{*}$ \\
\hline $\mathrm{HbA} 1 \mathrm{c} \%$ & $5.06(0.27)$ & $6.22(0.934)$ & $0.0001^{*}$ \\
\hline
\end{tabular}

\# Chi-square test; *Kruskal-Wallis test; ††One-way analysis of variance (ANOVA);

MPOD sqrt; $P$ values reflect the probability associated with the given F statistic. Data is weighted. Sig., significance.

†Age: the age division corresponds to groupings used in previously published cohort studies. ${ }^{38}$

* MPOD, $P$ values are reported using MPOD square root transformation (sqrt).

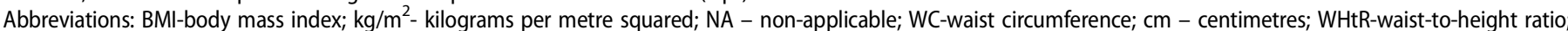
WHpR-waist-to-hip ratio. HbA1c-glycated hemoglobin; TC-Total cholesterol; HDL-High density lipoprotein; LDL-Low density lipoprotein; TG-Triglycerides; Non HDL- Total cholesterol minus HDL; CRP-C-reactive protein; $\mathrm{mmHg}$ - millimetres of mercury; mmol/L -millimoles per litre; nmol/L -nanomols per litre; mg/L-micrograms per litre. Normotensive ( $\leq 140 \mathrm{mmHg}$ systolic; $\leq 90 \mathrm{mmHg}$ diastolic); Hypertensive ( $>140 \mathrm{mmHg}$ systolic; $>90 \mathrm{mmHg}$ diastolic).

(primary, secondary or third level), alcohol intake, and serum TC to HDL ratio ( $p>.05$ for these variables; Table 1$)$.

Participants with diabetes were older, and more likely to be male with a current or past history of tobacco use. In general terms, the behavioral, clinical and anthropometric profile of these participants was poorer than that observed in the control group, with lower levels of physical activity, greater levels of obesity and higher prevalence of hypertension and cataract. Similarly, serum analysis revealed that participants with diabetes were typically more hyperglycemic, more dyslipidemic and displayed greater anti-inflammatory marker elevation (serum vitamin D) and inflammatory marker elevation (CRP), than the control group.

\section{Biomarker associations with MPOD among participants with diabetes}

\section{Demographic and behavioral factors}

Smoking was the only demographic or behavioral factor significantly associated with lower $\operatorname{MPOD}(\mathrm{F}(2,185)=6.019$, $p=.003)$. Post hoc analysis revealed that participants who never smoked had significantly higher normalized MPOD (mean $=0.235(0.148)$ ) compared with current smokers (mean $=0.124(0.113) ; \mathrm{t}(96) ;=3.58, p=.001)$. There was also a significant difference in MPOD between past (mean $=0.19[0.151]$ and current smokers ( $\mathrm{t}(116) ;=2.268$, $p=.025)$. However, there was no significant difference in 

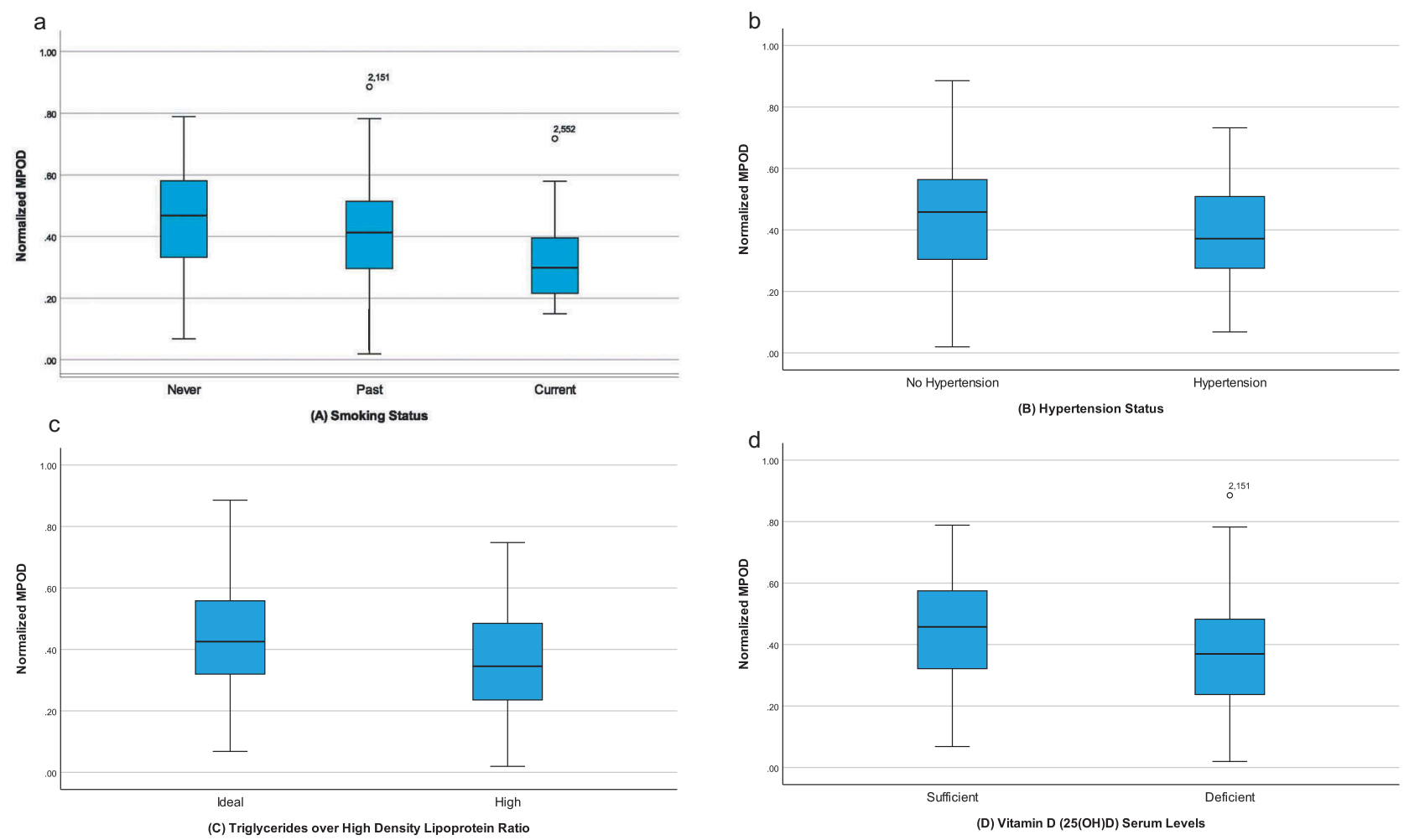

Figure 2. Box plots of MPOD by (a) Smoking status (b) Hypertension status (c) Triglyceride over High Density Lipoprotein ratio (d) Vitamin D 25(OH) D serum levels.

MPOD between non-smokers and past smokers ( $\mathrm{t}$ $(158)=1.723, p=.087) ;($ Figure 2a).

\section{Anthropometric and clinical biomarkers}

MPOD was negatively correlated with BMI, WC and WHtR (Pearson's correlation $=-0.202,-0.161,-0.189$ respectively, $p<.05$ for all), but not with WHpR (Pearson's $\mathrm{r}=-0.111$, $p>$.05). Cut-offs were applied to classify participants as obese and non-obese for all anthropometric measures, including BMI, $\mathrm{WC}, \mathrm{WHtR}$ and $\mathrm{WHpR} .{ }^{30} \mathrm{MPOD}$, however, was not significantly different in individuals with excess compared with normal adiposity indices for all anthropometric measures $(p>.05$ for all; Table 2). Although MPOD tended to be lower in subjects with cataracts, and in those with elevated WHtR and WHpR (all trending towards significance), only hypertension emerged in the univariate linear regression analysis as associated with lower MPOD (Table 2; Figure 2b).

\section{Serum biomarkers}

MPOD was significantly lower among participants with a raised TG to HDL ratio [Mean $=0.172(0.140)]$ compared to those with ideal levels (Mean $=0.215(0.152)$; $\mathrm{t}(185) ;=2.080, p=.039$; Table 3; Figure 2c). ANOVA revealed no significant difference in MPOD between those with high and low TC, HDL, LDL, triglycerides, non-HDL and TC/HDL ( $p=.287-0.946)$ (see Table 3). Participants who were vitamin $\mathrm{D}$ deficient had significantly lower MPOD $[$ mean $=0.173(0.148)]$ compared to participants who had sufficient levels [mean $=0.226(0.145) ; \mathrm{t}(185),=-2.796$, $p=.006$; Table 3; Figure 2d]. Figure 3 shows a significant positive relationship between normalized MPOD and serum

\section{Multivariate model}

\section{Demographic and behavioural factors}

Smoking remained a strong, negative predictor of MPOD after adjusting for covariates. Current smoking was significantly associated with lower MPOD (Beta co efficient $=-0.097 ; p=.022$; Table 4 ).

\section{Anthropometric and physical biomarkers}

The presence of cataract remained the only clinical parameter to be negatively associated with MPOD in a diabetic population after adjusting for covariates (Beta co efficient $=-0.078$; $p<.049)$. None of the other anthropometric or clinical parameters (WHtR, hypertension, diabetic retinopathy or duration of disease) remained significantly associated with MPOD in this model $(p>.05$ for all).

\section{Serum biomarkers}

Vitamin D remained a significant and positive predictor of MPOD in the multivariate model, although this was a subtle effect (Beta co efficient $=0.001 ; p=.029$ ). None of the other serum biomarkers (TG/HDL, HbA1c or CRP) remained significantly associated with MPOD ( $p>.05$ for these variables).

The correlates of MPOD identified as significant in the multivariate regression model (smoking, cataracts and low vitamin D status) contributed $18.5 \%$ of the overall variability in MPOD status amongst patients with Type 2 diabetes, (F $\left.(13,146)=2.545, p=.003 ; \mathrm{R}^{2}=0.185\right)$. 
Table 2. MPOD according to Anthropometric and Clinical Biomarkers in a Diabetic Population (normalized MPOD).

\begin{tabular}{|c|c|c|c|c|c|c|}
\hline & $\begin{array}{c}n \\
188\end{array}$ & $\begin{array}{c}\text { Mean (SD) } \\
\text { MPOD }\end{array}$ & $25^{\text {th }}$ & $50^{\text {th }}$ & $75^{\text {th }}$ & $\begin{array}{c}\text { sig } \\
p\end{array}$ \\
\hline \multicolumn{7}{|c|}{$\begin{array}{l}\text { Anthropometric \& Clinical Biomarkers } \\
\text { BMI }\left(\mathbf{k g} / \mathrm{m}^{2}\right)\end{array}$} \\
\hline Ideal $(\leq 30)$ & 122 & $0.200(0.148)$ & 0.087 & 0.177 & 0.304 & $0.964+\dagger$ \\
\hline \multicolumn{6}{|l|}{ WC (cm) } & \multirow{2}{*}{$0.101+\dagger$} \\
\hline Excess $(>102 \mathrm{M},>88 \mathrm{~F})$ & 132 & $0.191(0.151)$ & 0.076 & 0.162 & 0.264 & \\
\hline \multicolumn{7}{|l|}{ WHtR } \\
\hline Ideal $(\leq 0.57 \mathrm{M}, \leq 0.53 \mathrm{~F})$ & 45 & $0.237(0.164)$ & 0.088 & 0.228 & 0.379 & \multirow[t]{2}{*}{$0.073+\dagger$} \\
\hline Excess $(>0.57 \mathrm{M},>0.53 \mathrm{~F})$ & 142 & $0.189(0.142)$ & 0.086 & 0.172 & 0.267 & \\
\hline \multicolumn{7}{|l|}{ Blood Pressure $(\mathrm{mmHg})$} \\
\hline Normotensive $(\leq 140 / 90)$ & 83 & $0.228(0.166)$ & 0.090 & 0.210 & 0.324 & \multirow[t]{2}{*}{$0.043+\dagger$} \\
\hline Hypertensive $(>140 / 90)$ & 105 & $0.177(0.130)$ & 0.075 & 0.138 & 0.259 & \\
\hline \multicolumn{7}{|l|}{ Diabetic Retinopathy } \\
\hline
\end{tabular}

†† ANOVA was used to check for MPOD differences among anthropometric and physical biomarkers. $P$ values are reported using MPOD square root transformation (sqrt) (normalized MPOD) and reflect the probability associated with the given F statistic. Data is weighted. Sig., significance.

The following cut-offs were applied to indicate ideal or excess obesity measures and normotensive/hypertension for the following variables: BMI-body mass index; [ideal $\leq$ 30; excess $>30 \mathrm{~kg} / \mathrm{m}^{2}$ - kilograms per metre squared; WC-waist circumference; ideal $\leq 88 \mathrm{~F}$; $\leq 102 \mathrm{M}$; excess $>88 \mathrm{~F}$; $>102 \mathrm{M}$ cm - centimetres; WHtR-waist-to-height ratio; ideal $\leq 0.53 \mathrm{~F} ; \leq 0.57 \mathrm{M}$; excess $>0.57 \mathrm{~F} ;>0.53 \mathrm{M}$; WHpR-waist-to-hip ratio; ideal $\leq 0.85 \mathrm{~F} ; \leq 1.00 \mathrm{M}$; excess $>0.85 \mathrm{~F} ;>1.00 \mathrm{M} ; \mathrm{M}=\mathrm{Male} ; \mathrm{F}=\mathrm{Female} ;{ }^{30}$ Normotensive ( $\leq 140 \mathrm{mmHg}$ systolic; $\leq 90 \mathrm{mmHg}$ diastolic); Hypertensive (>140 $\mathrm{mmHg}$ systolic; $>90 \mathrm{mmHg}$ diastolic).

\section{Discussion}

Consistent with previous investigations, ${ }^{17,18}$ this study provides further evidence that patients with Type 2 diabetes have significantly lower MPOD, compared with non-diabetic controls. Additionally, MPOD was inversely associated with a range of behavioral, clinical and anthropometric biomarkers including smoking, hypertension and bodyweight. Body mass index, WHtR and WC were all negatively associated with MPOD on univariate analysis, in the Type 2 diabetes group, (Pearson's $\mathrm{r}, p<.05$ for all). Some novel relationships were observed among the serum biomarkers, with low serum vitamin D and raised TG/HDL ratio associated with low MPOD levels; findings not previously reported. Current smoking, the presence of cataract and low serum vitamin $\mathrm{D}$ persisted as predictors of low MPOD in the multivariate model, after adjusting for all other covariates, albeit collectively explaining just $18.5 \%$ of the variability in MPOD.

Our finding that hypertensive participants with diabetes had significantly lower MPOD compared to normotensive participants with diabetes is important given that hypertension is an established risk factor for the development and progression of DR. ${ }^{37}$ The association between MP and hypertension is not well documented; however, one study has reported a link between lower MPOD and a self-reported diagnosis of high blood pressure. $^{38}$ Chronic hypertension causes vascular endothelial shear stress and circumferential wall stress. ${ }^{39}$ This, in turn, leads to endothelial damage, increased ROS production and activation of inflammatory cascades. ${ }^{40}$ One recent study found lower levels of glutathione (GSH) and increased levels of 8-iso-prostaglandin $2 \alpha$ (8-iso-PGF2 $\alpha$ ), a marker of oxidative stress, in diabetes patients with hypertension, supporting the hypothesis that oxidative stress increases considerably in hypertension, especially as a diabetic co-morbidity. ${ }^{41}$ Endogenous antioxidants become depleted when both conditions coexist, which leads to an increased need for exogenous antioxidants (i.e. vitamins $\mathrm{C}$ and $\mathrm{E}$, carotenoids lutein, zeaxanthin \& meso-zeaxanthin) to balance redox status, which may explain our observation that hypertension in the presence of Type 2 diabetes may have an added negative impact on MPOD status on univariate analysis. While we did not reach statistical significance in multivariate analyses, future studies with larger cohorts could further investigate this finding.

The inverse relationship observed between adiposity and MPOD confirms previous findings among patients with Type 2 diabetes. ${ }^{18}$ Adipose tissue, visceral fat in particular; may act as a sink/reservoir for macular carotenoids, ${ }^{23}$ thereby influencing carotenoid concentrations in serum ${ }^{42}$ and subsequent retinal uptake. ${ }^{24}$ Distribution of body fat is also a significant factor, as it has been shown that concentrations of lutein and zeaxanthin are higher in abdominal fat, ${ }^{43}$ and abdominal adiposity is characteristic in Type 2 diabetes. Excess visceral fat also contributes to inflammation and oxidative stress due to the increased production of adipo-cytokines (Interleukin-1 (IL-1), Interleukin-6 (IL-6), Interleukin-8 (IL-8), tumor necrosis factor alpha (TNF-alpha)). ${ }^{7}$ The chronic low grade inflammation, associated with obesity and Type 2 diabetes leads to increased oxidative stress and further inflammation, putting a greater demand on antioxidant defences. Antioxidant defences may also be lower in overweight/Type 2 diabetic patients, due to their lower intake of antioxidant rich foods (e.g. fruits and vegetables), their increased utilisation of these molecules (e.g. increased inflammation/ROS in insulin dependent tissue such as the retina) and their impaired generation of other supportive anti-oxidants, reviewed by Savini et $\mathrm{al}^{44}$ which may collectively lead to 
Table 3. MPOD according to Serum Biomarkers in a Diabetic Population (normalized MPOD).

\begin{tabular}{|c|c|c|c|c|c|c|}
\hline & $\begin{array}{c}n \\
188\end{array}$ & $\begin{array}{c}\text { Mean (SD) } \\
\text { MPOD }\end{array}$ & $25^{\text {th }}$ & $50^{\text {th }}$ & $75^{\text {th }}$ & $\begin{array}{c}\text { sig } \\
p\end{array}$ \\
\hline \multicolumn{7}{|c|}{$\begin{array}{l}\text { Serum Biomarkers } \\
\text { TC (mmol/L) }\end{array}$} \\
\hline Ideal $\leq 5.00$ & 141 & $0.207(0.152)$ & 0.088 & 0.182 & 0.304 & \multirow[t]{2}{*}{$0.287+\dagger$} \\
\hline High $>5.00$ & 46 & $0.177(0.138)$ & 0.068 & 0.163 & 0.260 & \\
\hline \multicolumn{7}{|l|}{ HDL (mmol/L) } \\
\hline Ideal $>1.6$ & 27 & $0.203(0.138)$ & 0.089 & 0.184 & 0.275 & \multirow[t]{3}{*}{$0.785+\dagger$} \\
\hline \multirow{2}{*}{\multicolumn{6}{|c|}{ LDL (mmol/L) }} & \\
\hline & & & & & & \\
\hline Ideal $\leq 2.6$ & 127 & $0.20(0.147)$ & 0.076 & 0.179 & 0.297 & \multirow[t]{2}{*}{$0.946+\dagger$} \\
\hline High $>2.6$ & 10 & $0.199(0.154)$ & 0.087 & 0.0174 & 0.276 & \\
\hline \multicolumn{7}{|l|}{ TG $(\mathrm{mmol} / \mathrm{L})$} \\
\hline Ideal $\leq 1.7$ & 97 & $0.203(0.147)$ & 0.099 & 0.177 & 0.285 & \multirow[t]{2}{*}{$0.491+\dagger$} \\
\hline High $>1.7$ & 90 & $0.195(0.151)$ & 0.069 & 0.179 & 0.301 & \\
\hline \multicolumn{7}{|c|}{ Non HDL (mmol/L) } \\
\hline Ideal $\leq 3.4$ & 132 & $0.202(0.146)$ & 0.088 & 0.178 & 0.303 & \multirow[t]{2}{*}{$0.671+\dagger$} \\
\hline High $>3.4$ & 55 & $0.194(0.157)$ & 0.072 & 0.172 & 0.263 & \\
\hline \multicolumn{7}{|l|}{ TG/HDL C Ratio } \\
\hline Ideal $\leq 1.74$ & 118 & $0.215(0.152)$ & 0.100 & 0.181 & 0.314 & \multirow{2}{*}{$0.039+\dagger$} \\
\hline High $>1.74$ & 69 & $0.172(0.140)$ & 0.053 & 0.119 & 0.248 & \\
\hline \multicolumn{7}{|c|}{ Vitamin D (nmol/L) } \\
\hline Deficient $\leq 50$ & 96 & $0.173(0.148)$ & 0.056 & 0.181 & 0.234 & \multirow[t]{2}{*}{$0.006+\dagger$} \\
\hline Sufficient $>50$ & 91 & $0.226(0.145)$ & 0.103 & 0.209 & 0.336 & \\
\hline \multicolumn{7}{|l|}{ CRP (mg/L) } \\
\hline Ideal $\leq 3.0$ & 113 & $0.213(0.158)$ & 0.088 & 0.181 & 0.298 & \multirow[t]{3}{*}{$0.120+\dagger$} \\
\hline High >3.0 & 74 & $0.178(0.130)$ & 0.069 & 0.167 & 0.262 & \\
\hline \multicolumn{6}{|l|}{ HbA1c (\%) } & \\
\hline$\leq 6.0$ & 77 & $0.203(0.160)$ & 0.081 & 0.173 & 0.295 & \multirow[t]{2}{*}{$0.728+\dagger$} \\
\hline$>6.0$ & 97 & $0.190(0.139)$ & 0.081 & 0.177 & 0.259 & \\
\hline
\end{tabular}

††ANOVA was used to check for MPOD differences among serum biomarkers. $P$ values are reported using MPOD square root transformation (sqrt) (normalized MPOD) and reflect the probability associated with the given F statistic. Data is weighted. Sig., significance.

The following cut-offs were applied to serum levels: HDL, high density lipoprotein; [high risk $\leq 1.6$; low risk $>1.6$ millimoles per litre (mmol/L)]; LDL, low density lipoprotein; [high risk > 2.6; low risk $\leq 2.6 \mathrm{mmol} / \mathrm{L}$ ]; TC, total cholesterol; [high risk $>5.00$; low risk $\leq 5.00 \mathrm{mmol} / \mathrm{L}$; TG, triglycerides; [high risk $>1.7$; low risk $\leq 1.7 \mathrm{mmol} / \mathrm{L}$ ]; TG/HDL, triglyceride to high density lipoprotein ratio; [high risk $>1.74$; low risk $\leq 1.74 \mathrm{mmol} / \mathrm{L}$ ]; $\mathrm{TC} / \mathrm{HDL}$, total cholesterol to high density lipoprotein ratio; [high risk >3.5; low risk $\leq 3.5 \mathrm{mmol} / \mathrm{L}$ ]; Non-HDL, total cholesterol minus high density lipoprotein; [high risk >3.4; low risk $\leq$ $3.4 \mathrm{mmol} / \mathrm{L}$ ] as per $2016 \mathrm{ESC} / \mathrm{EAS}$ guidelines ${ }^{31}$; serum vitamin D $(25(\mathrm{OH}) \mathrm{D})$ levels in nanomoles per litre ( $\left.\mathrm{nmol} / \mathrm{L}\right)$ [deficient $\leq 50$; sufficient $>50 \mathrm{nmol} / \mathrm{L}$ ] as per IOM vitamin D guidelines ${ }^{34}$; serum CRP levels in micrograms per litre $(\mathrm{mg} / \mathrm{L})$ [high $>3.00 \mathrm{mg} / \mathrm{L}$; ideal $\left.\leq 3.00 \mathrm{mg} / \mathrm{L}\right]^{35}$; and $\mathrm{HbA1c}(\mathrm{glycated}$ hemoglobin) in millimoles per $\mathrm{mol}(\mathrm{mmol} / \mathrm{mol})$ [high $>6.00 \%$; ideal $\leq 6.00 \%(42.1 \mathrm{mmol} / \mathrm{mol})$ as per American Diabetes Association guidelines. ${ }^{27}$

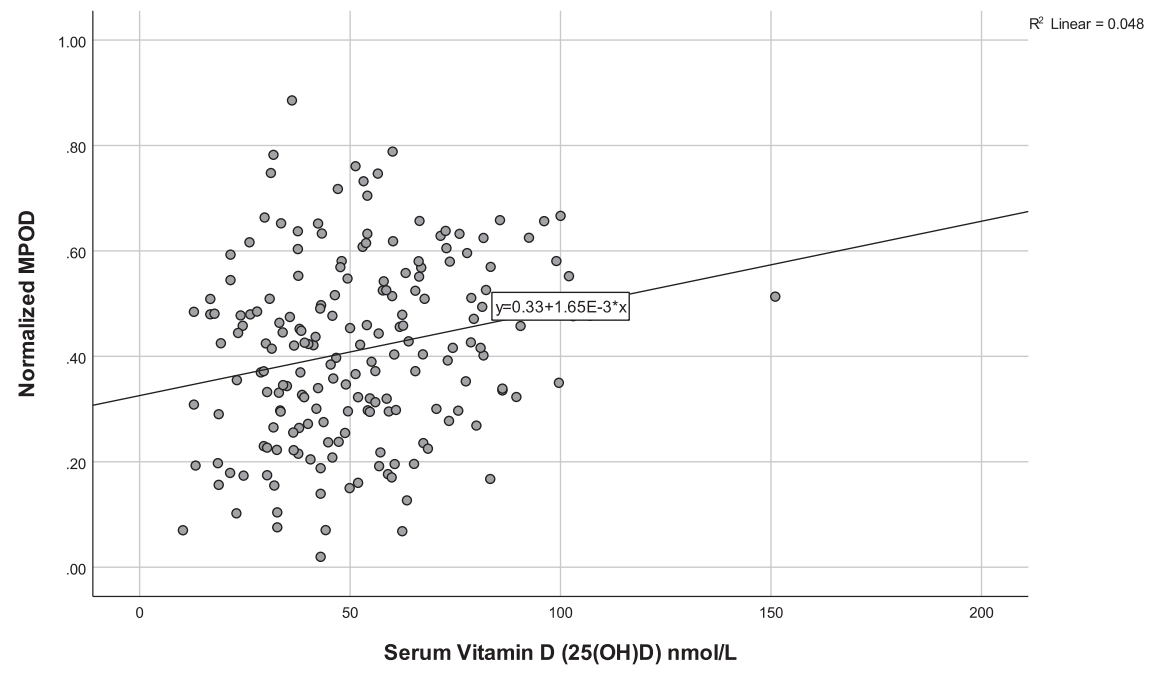

Figure 3. Scatterplot showing a significant positive relationship between normalized MPOD and Vitamin D (25(OH) D) serum levels.

MPOD depletion..$^{45}$ Dietary intake of lutein and zeaxanthin was not, however, assessed as part of the TILDA study (this limitation is discussed further below).

Of interest, and to our knowledge a novel finding; is that MPOD was significantly lower for participants with a raised TG to HDL ratio. This observation is important given that Type 2 diabetes patients commonly display an altered lipoprotein profile, termed diabetic dyslipidemia (i.e. raised TGs and low HDL), and that diabetes patients in the current study had indeed significantly higher TGs and significantly lower HDL serum lipid levels than the non-diabetic control group. The characteristic lipid profile of individuals with Type 2 diabetes ${ }^{46}$ may have important implications for MP levels in the eye, as dietary carotenoids are transported on circulating 
Table 4. Multivariate Relationship between Behavioral, Anthropometric, Clinical, Serum Biomarkers and MPOD in a Diabetic population $(n=188)$.

\begin{tabular}{|c|c|c|c|c|}
\hline Independent & Unstandardized & & & MPOD sqrt \\
\hline Variable & Beta Coefficient & Std Error & $T$ & $p$ \\
\hline Constant & 0.428 & 0.197 & 2.175 & 0.031 \\
\hline Age & 0.001 & 0.002 & 0.700 & 0.485 \\
\hline Sex* (Female) & -0.007 & 0.025 & -0.259 & 0.796 \\
\hline \multicolumn{5}{|l|}{ Smokingt } \\
\hline Past & -0.028 & 0.031 & -0.913 & 0.363 \\
\hline Current & -0.097 & 0.042 & -2.316 & 0.022 \\
\hline $\mathrm{WH} t \mathrm{R}$ & -0.192 & 0.183 & -1.046 & 0.297 \\
\hline Cataracts $\neq$ (Yes) & -0.078 & 0.039 & -1.988 & 0.049 \\
\hline Vitamin D $\mathrm{nmol} / \mathrm{L}$ & 0.001 & 0.001 & 2.204 & 0.029 \\
\hline CRP $\mathrm{mg} / \mathrm{L}$ & 0.001 & 0.001 & 1.382 & 0.169 \\
\hline TG/HDL Ratio & -0.015 & 0.013 & -1.170 & 0.244 \\
\hline $\mathrm{HbA1c} \%$ & -0.006 & 0.017 & -0.373 & 0.710 \\
\hline Duration (years) & 0.003 & 0.003 & 1.093 & 0.276 \\
\hline Retinopathy†t (Yes) & -0.092 & 0.058 & 1.585 & 0.115 \\
\hline Hypertension $\neq \neq$ (No) & 0.035 & 0.027 & 1.302 & 0.195 \\
\hline
\end{tabular}

$r^{2}=0.185 ; \mathrm{F}=2.545 ; p=0.003$. Dependent variable $=$ MPOD sqrt (normalized MPOD); Data is weighted. Std. Error, Standard Error.

${ }^{*}$ Male = control group; $\dagger$ Never smoked $=$ control group; $\neq$ No

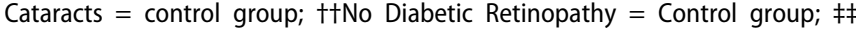
Hypertension $=$ Control group.

Abbreviations: CRP - C-reactive protein; HbA1c- glycated hemoglobin; mg/L micrograms per litre; $\mathrm{nmol} / \mathrm{L}$ - nanomoles per litre; WHtR- waist to height ratio; TG/HDL- triglyceride to high density lipoprotein ratio.

lipoproteins. ${ }^{24}$ The general consensus is that xanthophylls associate with HDL, ${ }^{47}$ and that HDL levels are therefore important for the efficient delivery and uptake of lutein and zeaxanthin to the eye. ${ }^{24}$ The relationship between MPOD and serum lipid levels has previously been investigated in patients with diabetes, with a marginal negative association between MPOD and TGs and a marginal positive association between MPOD and HDL observed ( $p<.08$ for both). ${ }^{17}$ We previously reported significantly lower levels of MPOD in patients with Type 2 versus Type 1 diabetes, and noted significantly lower HDL values within the Type 2 diabetes group, postulating that lower HDL levels may have mediated this difference. ${ }^{18}$ More recently, the DiVFuSS study, ${ }^{19}$ has demonstrated significant improvements in serum LDL, HDL and TGs, in a group of patients with diabetes who participated in a 6-month randomized control trial (RCT). The coincident increase in MPOD observed in the intervention group may have been partially mediated by these favourable changes in lipid profile. ${ }^{24} \mathrm{We}$ acknowledge, however, that the lack of dietary information on carotenoid intake is a limitation of the current study, (discussed in further detail below), as MPOD is influenced by both lutein and zeaxanthin intake as well as transport and assimilation (i.e. mediated by HDL) in the target tissue. This information would have added to the interpretation of our findings. While we found that lower MPOD was associated with raised serum TG/HDL levels on univariate analysis $(p=.039)$, serum TG/HDL did not remain as a predictor of MPOD in multivariate analyses. Future studies, however, based on a larger number of diabetic participants could further investigate this finding.

Our findings in relation to smoking are not surprising given that smoking is associated with increased oxidative stress, not only through the increased systemic production of ROS, but also through weakening of the antioxidant defence systems. ${ }^{48}$ The reported associations between cigarette smoking and DR, however, are more variable, with some studies reporting an association, ${ }^{49}$ while others have found no such relationship. ${ }^{50}$ Chronic hyperglycemia causes oxidative stress, so the increased production of ROS in diabetes may be compounded further by smoking, another important source of free radicals. Exposure to cigarette smoking causes profound oxidative damage to human retinal pigment epithelium (RPE) cells. ${ }^{51}$ Interestingly, we found no difference in MPOD between previous smokers and nonsmokers, perhaps indicating that MPOD repletion is possible in diabetes patients through smoking cessation.

Cataract status remained a predictor of low MPOD in the multivariate model in line with previous observations. ${ }^{52,53}$ The marginal statistical significance of this association in the univariate model $(p=.068)$ was more than likely limited by the small sample size in the current study ( $n=26$ with cataracts). The evidence that carotenoids, lutein and zeaxanthin, are protective against the development of cataract, however, is well documented, ${ }^{52,53}$ suggesting the possibility of a causal role for MPOD depletion in the pathogenesis of cataract development in diabetes. With aging there is a natural decrease in the production of antioxidants and antioxidant enzymes, and a concomitant increase in phototoxic chromophores in the lens. ${ }^{54}$ Phototoxic reactions, whether caused by endogenous or exogenous singlet oxygen photosensitizers, lead to a modification of lens proteins, which eventually causes opacification of the lens (i.e. cataractogenesis) (reviewed by Roberts \& Dennison.) ${ }^{54}$ The phototoxic reaction damage can be prevented by the appropriate antioxidant quenchers. Lutein and zeaxanthin both accumulate in the lens ${ }^{55}$ and research has shown a lower prevalence of nuclear cataract amongst those with higher intakes of xanthophylls. ${ }^{53}$ Furthermore, findings from the age related eye disease study (AREDS 2) revealed that participants in the lowest quintile of dietary lutein/zeaxanthin intake experienced slower cataract progression with carotenoid supplementation. ${ }^{52}$ Although the development of cataract is an age-related phenomenon, other factors appear to influence their progression including poor diet, smoking, ultra violet light exposure and metabolic factors. In the current study, a greater percentage of patients with diabetes had cataract (13.83\%) compared with controls (6.51\%), $(p<.0001)$. Cataract status does not appear to relate to MPOD levels among non-diabetic individuals, ${ }^{38}$ suggesting a relationship that is particular to cataract in the presence of Type 2 diabetes, which may impact MPOD levels in this patient group. To our knowledge, this is the first study to report an association between low MPOD and the presence of cataract in diabetes.

That vitamin $\mathrm{D}$ emerged as a positive predictor of MPOD in Type 2 diabetes after controlling for other covariates represents a particularly novel and interesting finding. Although the best known function of vitamin $\mathrm{D}$ is to help the body absorb and use calcium, other important roles include protection of the eye during inflammation, oxidative stress, fibrosis, and angiogenesis. ${ }^{56}$ Vitamin $D$ insufficiency is common amongst the general population, and particularly amongst those who are obese ${ }^{57}$ or who have diabetes. ${ }^{58}$ Our findings support this observation as both the control and Type 2 
diabetes group had mean vitamin D levels which fell well below the optimal recommended level, ${ }^{59}$ and as the participants with Type 2 diabetes had significantly lower serum vitamin D compared with the control group $(p<.0001)$. Vitamin D receptors (VDRs) are expressed in the eye, including the RPE ${ }^{60}$ which suggests that vitamin $\mathrm{D}$ is biologically relevant to the eye. ${ }^{61}$ Research shows that human adult RPE cells (ARPE-19) also express the 1a-hydroxylase enzyme required to convert $25(\mathrm{OH}) \mathrm{D}$ to its biologically active $1,25(\mathrm{OH})_{2}$ D form. $^{62}$

The ability to inhibit neovascularisation has also led researchers to examine vitamin D's involvement in DR development. ${ }^{63}$ Serum vitamin $\mathrm{D}$ concentrations have previously been found to be inversely related to the severity of retinopathy in patients with diabetes, ${ }^{61}$ with this study suggesting that the measurement of serum $1,25(\mathrm{OH})_{2} \mathrm{D}_{3}$ concentrations might be helpful in predicting retinopathy progression, and that a detailed ophthalmologic examination is indicated for diabetes patients whose serum vitamin D levels are low. ${ }^{61}$ The DiVFuSS study recently examined the effects of supplementation with a novel multicomponent nutritional supplement, which included vitamin $\mathrm{D}$ and the antioxidants lutein and zeaxanthin, on ocular health and visual function in a group of participants with diabetes. ${ }^{19}$ Individuals receiving the DiVFuSS formula improved on all measures of visual function, and although not statistically significant $(p=.07)$, four subjects were downgraded from moderate to mild non proliferative DR following the intervention, while one subject on placebo was upgraded from mild to moderate non proliferative DR over the same period. ${ }^{19}$ Positive outcomes from DiVFuSS may in part be due to supplementation with a compound that specifically targets both inflammation and oxidative stress. It is plausible that these findings may have been mediated by enhancements in MPOD (27\% mean increase in DiVFuSS group vs $2 \%$ mean decrease in placebo group), and by vitamin D's attenuating effect on inflammation with reductions in serum high sensitivity (hs)-CRP (60\% mean decrease in DiVFuSS group vs $11 \%$ mean decrease in placebo group). ${ }^{19}$ Although CRP levels were significantly higher in participants with diabetes $[$ mean $=5.23(11.94)]$, compared with non-diabetic controls $[$ mean $=2.83(6.95)],(p=.0001)$, in our study, MPOD was not significantly different in diabetic participants with an elevated CRP level compared with ideal levels $(p=.120$; Table 3$)$. These findings, however, warrant further investigation.

There are a number of important limitations to the current study which should be recognized. Firstly, the use of selfreported data is not ideal. Diabetes diagnosis was based on respondent's recall rather than health records. Concomitantly, respondents were not explicitly asked what type of diabetes they had. Instead patient medications (self-reported) and age at diagnosis were used to account for possible Type 1 cases, which may have led to some misclassification. The presence or absence of cataract was also based on patient's recall rather than direct examination. Secondly, small patient numbers in some of the sub-group analyses may have limited the statistical power to detect associations that may exist (Type II error possibility). It is worth noting that the prevalence of diagnosed and undiagnosed Type 2 diabetes in these older adults resident in Ireland was found to be relatively low compared to other populations ( $8.6 \%$ and $0.9 \%$ respectively), which would account for low participant numbers in the current study. ${ }^{10,28}$ Another limitation was that dietary intake of the macular carotenoids was also not assessed, therefore, it was not possible to control for potential confounding from variable intake of lutein and zeaxanthin. Macular pigment constituent carotenoids cannot be synthesised de novo in humans, therefore, lower levels of MPOD may be experienced in participants with poor dietary intake of antioxidants. Mares et $\mathrm{al}^{64}$ found that MPOD was directly related to dietary intake of carotenoids, lutein and zeaxanthin, but even more strongly with serum levels, suggesting that unmeasured physical and medical factors may also influence the uptake, distribution and utilization of lutein and zeaxanthin. ${ }^{64}$ The absence of serum analysis of lutein and zeaxanthin was also a weakness in our study. Furthermore, it is worth noting that measures of MP are subject to genetic variation. MPOD is a multi-factorial phenotype, associated with variation in genes related to carotenoid transport, uptake and metabolism, and may be independent of known dietary and health influences in MPOD. ${ }^{65}$ The MP determinants reported herein (current smoking, presence of cataracts and vitamin D status) explained $18.5 \%$ of the overall variability in MPOD, in participants with diabetes. Diet is an important determinant of MPOD, therefore, cautionary interpretation of our findings is advised. Finally, while the current study used a large, nationally representative population, MPOD was only measured on participants who were able to attend a health center.

Despite these drawbacks, there were a number of strengths to the current analysis. The design of the TILDA study is a particular strength, in particular the selection of participants from which our diabetes and controls were drawn, which was representative of the Irish population aged 50 and over. Serum lipoproteins (HDL, TG/HDL) and inflammatory markers (vitamin D, CRP) were analyzed and blood pressure was measured, which represents an advance on previous research carried out, research which was based on self-reported doctors' diagnosis of high cholesterol and hypertension. ${ }^{38}$ The additional use of $\mathrm{HbAlc}$ helped identify undiagnosed and pre-diabetes cases. Finally, anthropometric measures such as WtHtR and WHpR, were used to analyse overweight/obesity in conjunction with BMI and WC.

Overall our findings suggest that individuals with Type 2 diabetes have lower MP relative to healthy controls, although the clinical importance of the observed level of difference is questionable. Future studies with larger cohorts could further investigate this finding, as the difference in MPOD, although significant $(p=.047)$, was marginal. Hyperglycemia and other anthropometric, metabolic and clinical correlates associated with diabetes (e.g. excess adiposity, dyslipidemia, hypertension, and cataract), may relate to a state of chronic oxidative stress and inflammation, processes which also underlie many of the functional alterations in retinal vasculature in DR. Both over utilization (i.e. in response to elevated oxidative stress/ inflammation) and under supply of antioxidant nutrients (dietary deficiency, excess adiposity, and dyslipidemia) may contribute to lower levels of MP in the diabetic retina. Clinical benefits may be realised through the early identification of 
MPOD depletion in Type 2 diabetes. Given the borderline statistical significance of many of our findings, more work needs to be done to verify and refine our understanding of the observed relationships. The MPOD difference of 0.053 OD in participants with sufficient vitamin $\mathrm{D}(>50 \mathrm{nmol} / \mathrm{L})$ versus deficient levels $(\leq 50 \mathrm{nmol} / \mathrm{L})$, although significant $(p<.006)$, is not clinically meaningful as it stands. MPOD measurement is not routinely available, however, the capacity of commonlymeasured surrogate serum biomarkers (HDL, TG/HDL, vitamin D), and anthropometric measurements (WHtR, WC) to identify people with diabetes at risk of low MP merits further consideration. The novel and important findings reported herein should now be subject to further research, to better understand the nature of any relationships that may exist.

\section{Acknowledgments}

The authors would like to thank The Irish Longitudinal Study on Aging (TILDA) for the support received and are grateful to all of the TILDA respondents for participating in the study.

\section{Declaration of interest}

No potential conflict of interest was reported by the authors.

\section{References}

1. Carracher AM, Marathe PH, Close KL. International Diabetes Federation 2017. J Diabetes. 2018;10:353-56. doi:10.1111/17530407.12644.

2. Kaiser AB, Zhang N, Van Der Plumm W. Global Prevalence of Type 2 Diabetes over the Next Ten Years (2018-2028). Am Diabetes Assoc. 2018;67:202-LB. doi:10.2337/db18-202-LB.

3. Lee R, Wong TY, Sabanayagam C. Epidemiology of diabetic retinopathy, diabetic macular edema and related vision loss. Eye Vis. 2015;2:17. doi:10.1186/s40662-015-0026-2.

4. Kowluru RA, Chan P-S. Oxidative stress and diabetic retinopathy. J Diabetes Res. 2007;2007:43603.

5. Brownlee M. Biochemistry and molecular cell biology of diabetic complications. Nature. 2001;414:813-20. doi:10.1038/414813a.

6. Al-Kharashi AS. Role of oxidative stress, inflammation, hypoxia and angiogenesis in the development of diabetic retinopathy. Saudi J Ophthal. 2018;32:318-23. doi:10.1016/j.sjopt.2018.05.002.

7. Kwon H, Pessin J. Adipokines mediate inflammation and insulin resistance. Front Endocrinol. 2013;4:71. doi:10.3389/ fendo.2013.00071.

8. Semeraro F, Cancarini A, Rezzola S, Romano M, Costagliola C. Diabetic retinopathy: vascular and inflammatory disease. J Diabetes Res. 2015:2015. doi:10.1155/2015/582060.

9. Barber AJ, Lieth E, Khin SA, Antonetti DA, Buchanan AG, Gardner TW. Neural apoptosis in the retina during experimental and human diabetes. Early onset and effect of insulin. J Clinic Investig. 1998;102:783-91. doi:10.1172/JCI2425.

10. Beagley J, Guariguata L, Weil C, Motala AA. Global estimates of undiagnosed diabetes in adults. Diabetes Res Clinic Practice. 2014;103:150-60. doi:10.1016/j.diabres.2013.11.001.

11. Sies H. Oxidative stress: from basic research to clinical application. Am J Med. 1991;91:S31-S38. doi:10.1016/0002-9343(91)90281-2.

12. Bouayed J, Bohn T. Exogenous antioxidants-double-edged swords in cellular redox state: health beneficial effects at physiologic doses versus deleterious effects at high doses. Oxidative Med Cellular Longevity. 2010;3:228-37. doi:10.4161/oxim.3.4.12858.

13. Chew EY, Clemons TE, SanGiovanni JP, Danis R, Ferris FL, Elman M, Antoszyk A, Ruby A, Orth D, Bressler S. Lutein+ zeaxanthin and omega-3 fatty acids for age-related macular degeneration: the
Age-Related Eye Disease Study 2 (AREDS2) randomized clinical trial. JAMA-J Am Med Assoc. 2013;309:2005-15. doi:10.1001/ jama.2013.4997.

14. Li S-Y, Fung FK, Fu ZJ, Wong D, Chan HH, Lo AC. AntiInflammatory Effects of Lutein in Retinal Ischemic/Hypoxic Injury: in Vivo and In Vitro StudiesAnti-Inflammatory Effects of Lutein. Invest Ophthalmol Vis Sci. 2012;53:5976-84. doi:10.1167/iovs.12-10007.

15. Bernstein PS, Li B, Vachali PP, Gorusupudi A, Shyam R, Henriksen BS, Nolan JM. Lutein, zeaxanthin, and meso-zeaxanthin: the basic and clinical science underlying carotenoid-based nutritional interventions against ocular disease. Prog Ret Eye Res. 2016;50:34-66. doi:10.1016/j.preteyeres.2015.10.003.

16. Hu B-J, Hu Y-N, Lin S, Ma W-J, Li X-R. Application of lutein and zeaxanthin in nonproliferative diabetic retinopathy. Internat J Ophthalmol. 2011;4:303.

17. Lima VC, Rosen RB, Maia M, Prata TS, Dorairaj S, Farah ME, Sallum J. Macular pigment optical density measured by dual-wavelength autofluorescence imaging in diabetic and nondiabetic patients: a comparative study. Investig Ophthalmol Vis Sci. 2010;51:5840-45. doi:10.1167/iovs.09-4695.

18. Scanlon G, Connell P, Ratzlaff M, Foerg B, McCartney D, Murphy A, O'Connor K, Loughman J. Macular pigment optical density is lower in type 2 diabetes, compared with type 1 diabetes and normal controls. Retina. 2015;35:1808-16. doi:10.1097/ IAE.0000000000000551.

19. Chous AP, Richer SP, Gerson JD, Kowluru RA. The diabetes visual function supplement study (DiVFuSS). Br J Ophthalmol. 2016;100:227-34. doi:10.1136/bjophthalmol-2014-306534.

20. Crosby-Nwaobi R, Hykin P, Peto T, Sivaprasad S. An exploratory study evaluating the effects of macular carotenoid supplementation in various retinal diseases. Clinic Ophthalmol (Auckland, NZ). 2016;10:835.

21. Moschos MM, Dettoraki M, Tsatsos M, Kitsos G, Kalogeropoulos C. Effect of carotenoids dietary supplementation on macular function in diabetic patients. Eye Vis. 2017;4:23. doi:10.1186/ s40662-017-0088-4.

22. Castro AVB, Kolka CM, Kim SP, Bergman RN. Obesity, insulin resistance and comorbidities? Mechanisms of association. Arq Bras Endocrinol Metabol. 2014;58:600-09. doi:10.1590/00042730000003223.

23. Hammond BR, Ciulla TA, Snodderly DM. Macular pigment density is reduced in obese subjects. Invest Ophthalmol Vis Sci. 2002;43:47-50

24. Connor WE, Duell PB, Kean R, Wang Y. The prime role of HDL to transport lutein into the retina: evidence from HDL-deficient WHAM chicks having a mutant ABCA1 transporter. Invest Ophthalmol Vis Sci. 2007;48:4226-31. doi:10.1167/iovs.06-1275.

25. Kearney PM, Cronin H, O'Regan C, Kamiya Y, Savva GM, Whelan B, Kenny R. Cohort profile: the Irish longitudinal study on ageing. Internat J Epidemiol. 2011;40:877-84. doi:10.1093/ije/ dyr116.

26. Kenny RA, Whelan BJ, Cronin H, Kamiya Y, Kearney P, O'Regan C, Ziegel M. The design of the Irish longitudinal study on ageing. (TILDA). Dublin, Ireland: Trinity College Dublin; 2010 [accessed 2018 Sep 24]. https://tilda.tcd.ie/publications/reports/ pdf/Report_DesignReport.pdf.

27. Association AD. 2. Classification and diagnosis of diabetes. Diabetes Care. 2015;38:S8-S16. doi:10.2337/dc15-S005.

28. Leahy S, O'Halloran A, O'Leary N, Healy M, McCormack M, Kenny R, O'Connell J. Prevalence and correlates of diagnosed and undiagnosed type 2 diabetes mellitus and pre-diabetes in older adults: findings from the Irish Longitudinal Study on Ageing (TILDA). Diabetes Res Clinic Pract. 2015;110:241-49. doi:10.1016/j.diabres.2015.10.015.

29. Nolan JM, Kenny R, O’Regan C, Cronin H, Loughman J, Connolly EE, Kearney P, Loane E, Beatty S. Macular pigment optical density in an ageing Irish population: the Irish Longitudinal Study on Ageing. Ophthal Res. 2010;44:131-39. doi:10.1159/000315531. 
30. Organization WH. Waist circumference and waist-hip ratio: report of a WHO expert consultation, Geneva (Switzerland); 8-11 December 2008. (2011) [accessed 2018 Oct 13]. http:// whqlibdoc.who.int/publications/2011/9789241501491_eng.pdf.

31. Catapano AL, Graham I, De Backer G, Wiklund O, Chapman MJ, Drexel H, Hoes AW, Jennings CS, Landmesser U, Pedersen TR. ESC/ EAS guidelines for the management of dyslipidaemias. Eur Heart J. 2016;2016(37):2999-3058. doi:10.1093/eurheartj/ehw272.

32. Wellen KE, Hotamisligil GS. Inflammation, stress, and diabetes. J Clinic Investig. 2005;115:1111-19. doi:10.1172/JCI25102.

33. Wang X, Bao W, Liu J, Ouyang YY, Wang D, Rong S, Xiao X, Shan ZL, Zhang Y, Yao P, et al. Inflammatory markers and risk of type 2 diabetes: a systematic review and meta-analysis. Diabetes Care. 2013;36:166-75. doi:10.2337/dc12-0702.

34. Ross AC, Manson JE, Abrams SA, Aloia JF, Brannon PM, Clinton SK, Durazo-Arvizu RA, Gallagher JC, Gallo RL, Jones $\mathrm{G}$, et al. The 2011 report on dietary reference intakes for calcium and vitamin D from the Institute of Medicine: what clinicians need to know. J Clinic Endocrinol Metab. 2011;96:53-58. doi:10.1210/jc.2010-2704.

35. Koenig W, Sund M, Fröhlich M, H-G F, Löwel H, Döring A, Hutchinson WL, MB P. C-Reactive protein, a sensitive marker of inflammation, predicts future risk of coronary heart disease in initially healthy middle-aged men: results from the MONICA (Monitoring Trends and Determinants in Cardiovascular Disease) Augsburg Cohort Study, 1984 to 1992. Circulation. 1999;99:237-42.

36. Barrett A, Burke H, Cronin H, Hickey A, Kamiya Y, Kenny RA, Layte R, Maty S, McGee H, Morgan K. Fifty plus in Ireland 2011: first results from the Irish Longitudinal Study on Ageing. Dublin (Ireland): TILDA \& Trinity College. 2011 [accessed 2018 Oct 13]. https://epubs.rcsi.ie/psycholrep/45/.

37. Klein R, Klein BE, Moss SE, Davis MD, DeMets DL. Is blood pressure a predictor of the incidence or progression of diabetic retinopathy?. Arch Internal Med. 1989;149:2427-32. doi:10.1001/ archinte.1989.00390110033008.

38. Nolan JM, Feeney J, Kenny RA, Cronin H, O’Regan C, Savva GM, Loughman J, Finucane C, Connolly E, Meagher K. Education Is Positively Associated with Macular Pigment: the Irish Longitudinal Study on Ageing (TILDA) Education and The TILDA Study. Investig Ophthalmol Vis Sci. 2012;53:7855-61. doi:10.1167/iovs.11-9367.

39. Lu D, Kassab GS. Role of shear stress and stretch in vascular mechanobiology. J Royal Soc Interface. 2011;8:1379-85. doi:10.1098/rsif.2011.0177.

40. Crowley SD. The cooperative roles of inflammation and oxidative stress in the pathogenesis of hypertension. Antioxid Redox Signal. 2014;20:102-20. doi:10.1089/ars.2013.5258.

41. Pouvreau C, Dayre A, Butkowski EG, de Jong B, Jelinek HF. Inflammation and oxidative stress markers in diabetes and hypertension. J Inflamm Res. 2018;11:61. doi:10.2147/JIR.S148911.

42. Burke JD, Curran-Celentano J, Wenzel AJ. Diet and serum carotenoid concentrations affect macular pigment optical density in adults 45 years and older. J Nutr. 2005;135:1208-14. doi:10.1093/ jn/135.5.1208.

43. Chung H-Y, Ferreira ALA, Epstein S, Paiva SA, CastanedaSceppa C, Johnson EJ. Site-specific concentrations of carotenoids in adipose tissue: relations with dietary and serum carotenoid concentrations in healthy adults. Am J Clinic Nutr. 2009;90:533-39. doi:10.3945/ajcn.2009.27712.

44. Savini I, Catani MV, Evangelista D, Gasperi V, Avigliano L. Obesity-associated oxidative stress: strategies finalized to improve redox state. Internat J Mol Sci. 2013;14:10497-538. doi:10.3390/ ijms140510497.

45. Gruber M, Chappell R, Millen A, LaRowe T, Moeller SM, Iannaccone A, Kritchevsky SB, Mares J. Correlates of serum lutein+ zeaxanthin: findings from the Third National Health and Nutrition Examination Survey. J Nutr. 2004;134:2387-94. doi:10.1093/jn/134.9.2387.
46. Goldberg IJ. Diabetic dyslipidemia: causes and consequences. J Clinic Endocrinol Metab. 2001;86:965-71. doi:10.1210/jcem.86.3.7304.

47. Thomas SE, Harrison EH. Mechanisms of selective delivery of xanthophylls to retinal pigment epithelial cells by human lipoproteins. J Lipid Res. 2016;57:1865-78. doi:10.1194/jlr.M070193.

48. Isik B, Ceylan A, Isik R. Oxidative stress in smokers and non-smokers. Inhal Toxicol. 2007;19:767-69. doi:10.1080/08958370701401418.

49. Abdul-Ridha H. The Effect of Smoking on Some Microvascular Complications in Type 2 Diabetics. Mustansiriya Med J. 2010;9:35-39.

50. Klein R, Klein BE, Davis MD. Is cigarette smoking associated with diabetic retinopathy?. Am J Epidemiol. 1983;118:228-38. doi:10.1093/ oxfordjournals.aje.a113630.

51. Bertram KM, Baglole CJ, Phipps RP, Libby RT. Molecular regulation of cigarette smoke induced-oxidative stress in human retinal pigment epithelial cells: implications for age-related macular degeneration. Am J Physiol-Cell Physiol. 2009;297:C1200-C1210. doi:10.1152/ajpcell.00126.2009.

52. Chew EY, SanGiovanni JP, Ferris FL, Wong WT, Agron E, Clemons TE, Sperduto R, Danis R, Chandra SR, Blodi BA. Lutein/ zeaxanthin for the treatment of age-related cataract: AREDS2 randomized trial report no. 4. JAMA J Am Ophthalmol. 2013;131:843-50. doi:10.1001/jamaophthalmol.2013.4412.

53. Jacques PF, Chylack LT, Hankinson SE, Khu PM, Rogers G, Friend J, Tung W, Wolfe JK, Padhye N, Willett WC, et al. Longterm nutrient intake and early age-related nuclear lens opacities. Arch Ophthalmol. 2001;119:1009-19.

54. Roberts JE, Dennison J. The photobiology of lutein and zeaxanthin in the eye. J Ophthalmol. 2015;1-8.

55. Yeum K-J, Shang F, Schalch W, Russell RM, Taylor A. Fat-soluble nutrient concentrations in different layers of human cataractous lens. Curr Eye Res. 1999;19:502-05.

56. Reins RY, McDermott AM, Vitamin D. implications for ocular disease and therapeutic potential. Exp Eye Res. 2015;134:101-10. doi:10.1016/j.exer.2015.02.019.

57. Alaklabi AM, Alsharairi NA. Current Evidence on Vitamin D Deficiency and Metabolic Syndrome in Obese Children: what Does the Evidence from Saudi Arabia Tell Us?. Children (Basel). 2018;5:11.

58. Bayani MA, Akbari R, Banasaz B, Saeedi F. Status of Vitamin-D in diabetic patients. Caspian J Internal Med. 2014;5:40.

59. Holick MF. Vitamin D deficiency. New Eng J Med. 2007;357:266-81. doi:10.1056/NEJMra070553.

60. Johnson JA, Grande JP, Roche PC, Campbell RJ, Kumar RJ. Immuno-localization of the calcitriol receptor, calbinclin-D28k and the plasma membrane calcium pump in the human eye. Curr Eye Res. 1995;14:101-08.

61. Aksoy H, Akçay F, Kurtul N, Baykal O, Avci B. Serum 1, 25 dihydroxy vitamin D (1, $25(\mathrm{OH}) 2 \mathrm{D} 3), 25$ hydroxy vitamin $\mathrm{D}(25(\mathrm{OH})$ $\mathrm{D})$ and parathormone levels in diabetic retinopathy. Clinic Biochem. 2000;33:47-51. doi:10.1016/S0009-9120(99)00085-5.

62. Alsalem JA, Patel D, Susarla R, Coca-Prados M, Bland R, Walker EA, Rauz S, Wallace GR. Characterization of vitamin D production by human ocular barrier cells. Invest Ophthalmol Vis Sci. 2014;55:2140-47. doi:10.1167/iovs.13-13019.

63. Berridge MJJBJ. Vitamin D deficiency and diabetes. Biochem J. 2017;474:1321-32. doi:10.1042/BCJ20170042.

64. Mares JA, LaRowe TL, Snodderly DM, Moeller SM, Gruber MJ, Klein ML, Wooten BR, Johnson EJ, Chappell RJ. CAREDS Macular Pigment Study Group and Investigators. Predictors of optical density of lutein and zeaxanthin in retinas of older women in the Carotenoids in Age-Related Eye Disease Study, an ancillary study of the Women's Health Initiative. American J Clinic Nutr. 2006;84:1107-22. doi:10.1093/ajcn/84.5.1107.

65. Meyers KJ, Johnson EJ, Bernstein PS, Iyengar SK, Engelman CD, Karki CK, Liu Z, Igo RP Jr, Truitt B, Klein ML, et al. Genetic Determinants of Macular Pigments in Women of the Carotenoids in Age-Related Eye Disease StudyGenetic Predictors of MPOD. Investig Ophthalmol Visual Sci. 2013;54:2333-45. doi:10.1167/ iovs.12-10867. 